\title{
Performance Space of the Digital Performer/Reader inside Andy Campbell and Judi Alston's Digital Fiction the Nightingale's Playground
}

\author{
Gitanjali Roy \\ Assistant Professor, Department of English, Faculty of Liberal Arts, ICFAI University, \\ Tripura. Research Scholar, Dept of English, Tripura University. ORCID: oooo-0oo3-3672- \\ 3481.E-mail:itzgitz@gmail.com/gitanjaliroy@iutriipura.edu.in
}

\begin{abstract}
:
A digital performer has to negotiate with different kinds of affordances inside the space of a digital text. The Nightingale's Playground (2010), a digital fiction authored by Andy Campbell and Judi Alston offers the reader/player with four versions of the text centering on the protagonist Carl Robertson who tries hard to search for his lost school friend Alex Nightingale. The online texts ('Consensus Trance', 'Fieldwork Book') and the gaming version of the digital fiction ('Consensus Trance II') offer the reader different decisional platforms. This makes it a challenging task for the reader to connect the affordances of the digital text. At the same time, the offline pdf version of the digital fiction hints at Carl being affected by a psychological disorder. The paper shall focus on how a digital reader negotiates his/her position inside the digital text by decoding the programmer's/author's encoded plot.
\end{abstract}

Keywords: Digital, Performer, Text, Nightingale’s Playground, Reader, Player.

Digital Fiction is a branch of Digital Literature/E-Literature (Electronic Literature). Digital Fiction International Network defines Digital Fiction as, "fiction written for and read on computer screen that pursues its verbal, discursive and/or conceptual complexity through the digital medium, and would lose something of its aesthetic and semiotic function if it were removed from that medium". Reading Digital Fiction has evolved across the ages. Michael Joyce's afternoon: a story (1987) was the first hypertext fiction which made use of Storyspace program'. Victory Garden by Stuart Moulthrop was the first hypertext fiction ${ }^{2}$ where a graphical map directs the narrative of the text. In 2005, Lance Olsen and Tim Guthrie's web-based fiction 10:01 empowered the reader to navigate the text either using a chronological timeline or by clicking on the images of characters on screen. Kate Pullinger and Chris Joseph's Flight Path (2010) challenges the reader's perception. Each time the reader reads the text, he might choose different pathways, or sometimes the text itself provides different versions of itself. Each reading makes the reader perform in a different manner. The reader thus has to negotiate with his performance space. In this paper, the role of the performer shall be analysed through a reading of the Digital Fiction Nightingale's Playground.

In the printed texts, the reader acts passively where his reading is based on "eye movement and the periodic or arbitrary turning of pages", which according to Aarseth is non-ergodic literature; whereas in an ergodic literature "nontrivial effort is required to allow the reader to traverse the

(c) AesthetixMS 2021. This Open Access article is published under a Creative Commons Attribution Non-Commercial 4.0 International License (http://creativecommons.org/licenses/by-nc/4.o/), which permits non-commercial re-use, distribution, and reproduction in any medium, provided the original work is properly cited. For citation use the DOI. For commercial re-use, please contact editor@rupkatha.com. 
text". These terms have been coined by Espen J.Aarseth in his book Cybertext-Perspectives on Ergodic Literature. Inside a digital text, the reader is more interactive as compared to the printed text reader. In a printed text, there are only words as signifiers which are read in sequential order (sometimes it may contain images where the sequence is determined by the author); whereas a digital text, contains interface design, links, audio and visual effects (VFX and SFX 3 ), and so on. In What hypertexts can do that print narratives cannot (1992), Douglas argues "in print narratives" a reader's "reading experience begins with the first words of the narrative and is completed by the last words of the last page" whereas in hypertext fiction "readers are unable to begin reading without... making decision about the text - where their interests lie and which pathways through the text seems most likely to satisfy them". Thus, reading a digital text is also a part of performance for the digital readers.

Reading Digital Fiction is not just about accepting contents, it is a navigational experience where the performer is an active participant inside the digital space. As readers critically read a text, they are guided by their own experiences, and their knowledge influences the process of reading. The digital fictional narrative offers the audience a series of signifiers (images/words etc.) which allows the reader to make choices, linked through pathways which construct the storytelling in a non-linear way. There is no single sequential order in which the text can be read. In Nightingale's Playground, the reader has to keep on searching around the images, for her next clue to unlock the next chapter. Digital Fiction liberates the readers from the printed text boundaries and allows the reader to understand the text through words, graphics, sounds, color, sensation, etc. creating its own space within the story. The multiple signifiers stimulate the reader to choose their defined path. Their choice which is determined by the most attractive sign on-screen manipulates and helps to organize the narrative structures. Each sign is a voice inside the digital text because each sign signifies a certain meaning, which the reader decodes and thus the performer interacts with the multivocal space within the digital text.

Due to the non-linear or non-sequential feature of the digital text, the reader has to incorporate each part of the text, re-read them, and based on the suppositions relate each part to derive the complete meaning of the digital text. The centrality is never maintained as the reader sets her own desirable set of paths. When a reader cannot mark a coherent structure within the narrative, they tend to lose focus and get disoriented. Each reading orients the reader in different ways and the narrative is dependent on the performance space of the performer who often remains disoriented. Due to the disorientation of the reader, there are numerous narrative possibilities in approaching the story. Multiple paths and choices lead to multiple interpretations, resulting in a multiplicity of the reading. To read Nightingale's Playground and to understand the performity of the readers, Affordance theory shall be taken into consideration as the paper will try to figure out how affordances enable or repress user participation.

William Gaver in 1991 created a framework where he categorizes affordance ${ }^{4}$ into three typesFalse Affordances, Perceptible Affordances, and Hidden Affordances that separates affordances from perceptual information available. False affordances exist when the desired action is not possible to fulfil but the suggestion of the action is visible. This can happen when the user's device is not supporting the interface. For instance, 360-degree photos can be seen by rotating the device but if someone does not have an android phone, his device will show the option of the action, but the feature cannot be enjoyed. Thus there are limitations of the actions which are dependent on many affordances. False affordance is an apparent visual illusion that has no real function. The user is made to perceive some possibilities for action which is always non-existent in nature. Hidden affordance possesses possibilities for action but the user cannot perceive them. For instance, in certain mobile 
games, if a player double clicks on the screen then the plot moves forward. This is sometimes, hardly perceived by any user. Perceptible affordance provides the availability of action to the user so that he can perceive the possibilities of action and can thus decide their course of action accordingly. Gaver also distinguishes that "when no action and no perception of action is present then this is known as correct rejection" (Wesolko 1). When affordances are perceptible, they provide a direct link for the user to perceive and to take any action but when affordances are hidden or false, they can be misleading for the user and the user can make mistakes in taking proper decision to move forward. In digital texts, moving through different directions using the mouse and the keys are very important and thus the affordances provide a virtual decisional platform to the users. The experience of the text, inside the digital world, offers all- false affordances, perceptible affordances, and hidden affordances, which when not perceptible leads to mistakes and in the terms of Gaver leads to 'correct rejection'. But the question remains as to how the readers/audiences adapt themselves to the language of these affordances. This can be understood by a detailed analysis of the performer's approach to read Digital Fictions like Nightingale's Playground.

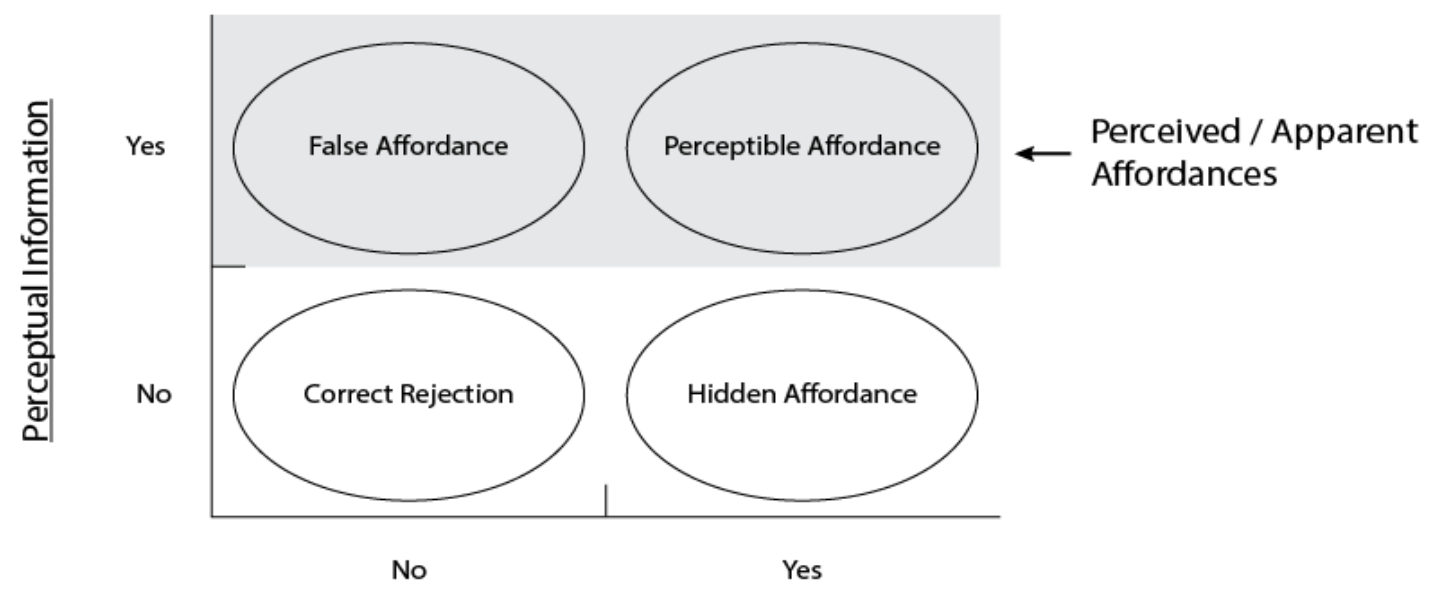

Affordance

Figure 1: Willam Gaver's framework on Affordance Theory

UK Digital Fiction titled Nightingale's Playground was created using Flash in 2010 by Andy Campbell and Judi Alston. It consists of four chapters: "Consensus Trance", an on-line click-andread interactive story; "Consensus Trance II", a downloadable $3 \mathrm{D}$ game controlled by the mouse and keyboard; a "Fieldwork Book", dragged across the screen using the mouse; and an e-book. Each individual part leads the reader/player to ponder upon the narrative centering on Carl Robertson, the protagonist, who tries hard to search for his lost school friend Alex Nightingale. Probably the title of the Digital Fiction derives its root from the lost friend who used to meet with Carl either in the school playground or in the protagonist's Gran's ground. Each part is interlinked and a proper understanding of the plot necessitates proper reading of all the parts. 


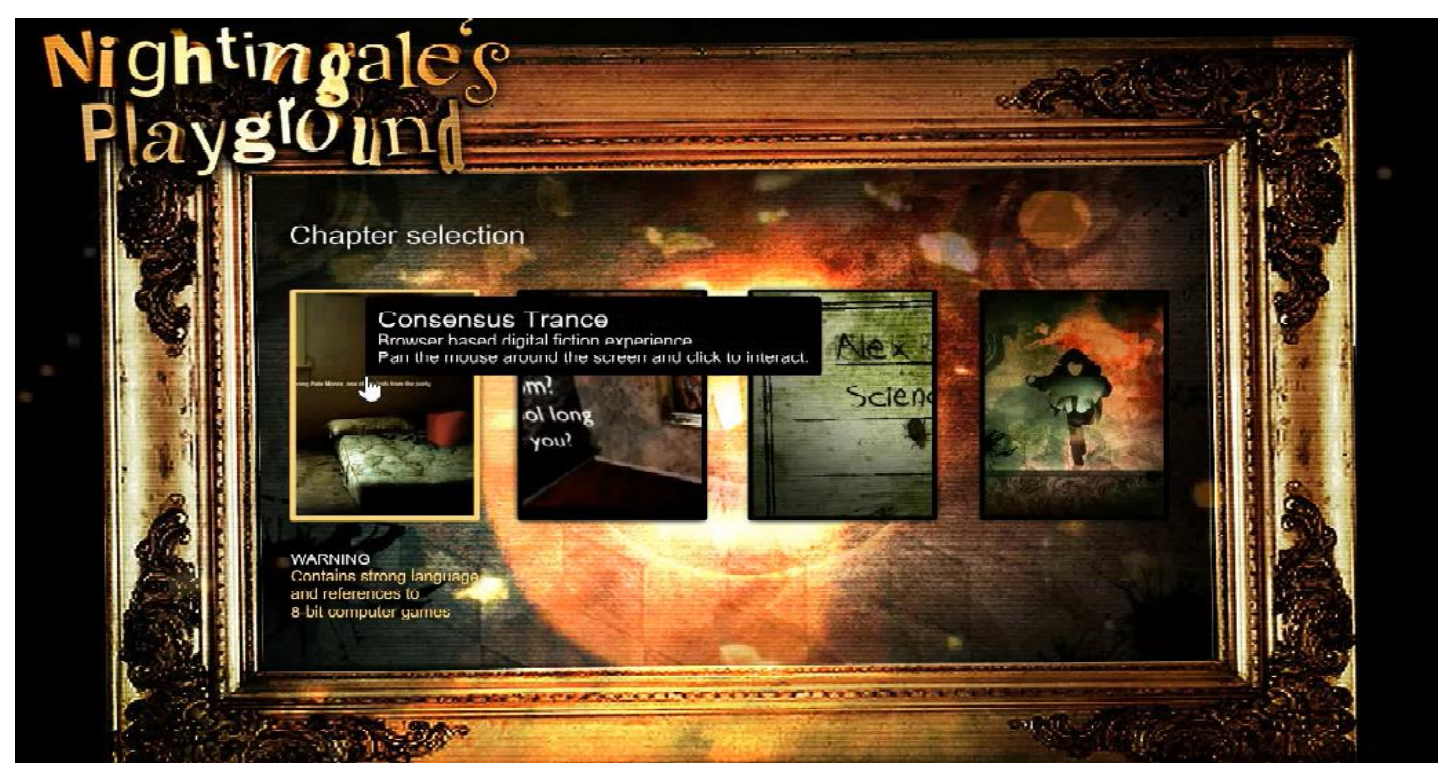

Figure 2: Four versions of the Nightingale's Playground

"Consensus Trance" introduces the reader to a dark room with an open window which is the source of visibility for the room, a bed with a red vanity case, and an easy-chair. The affordances provided by the programmer needs to be perceived by the reader. He has to perform inside the digital text. He has to hook for clues, use his logic, and connect the different clues to understand the plot. Those clues are the affordances provided by the programmer to the reader. The reader has to move his mouse to search for the narrative lines. At the top right corner of the screen, as depicted in Figure 3, the white-coloured bars indicate the chronological sequencing of the episodes. When the reader discovers all the episodes, the next plot unlocks, leaving the reader perplexed about the identity of Alex. Like Hamlet who keeps wandering "To be or not to be", Carl tries to resolve whether Alex is in his mind or is he a real person. Sometimes, the narrative may drive the reader confused as the reader has to wait for the plots to get downloaded and at times the narrative selection of the reader may be non-chronological. If the reader gets disoriented, if the affordances are not perceived by the reader, he has 'correct rejection'.

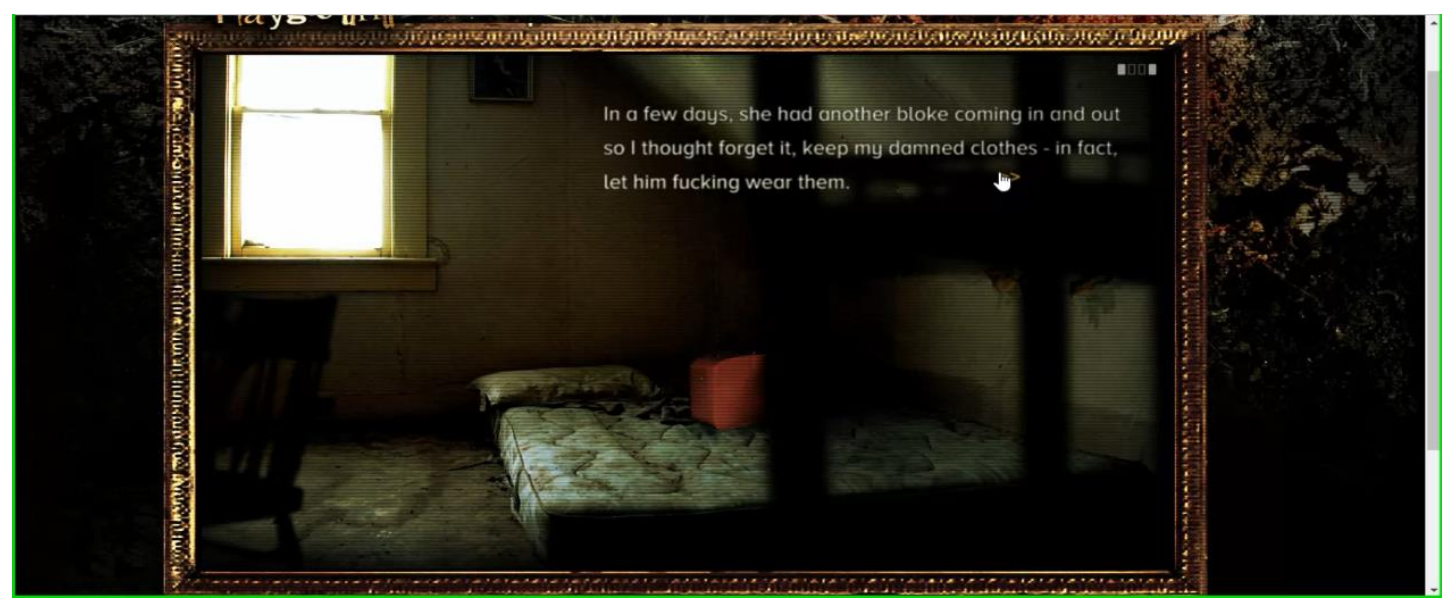

Figure 3: A visual from "Consensus Trance”, Nightingale's Playground 
"Consensus Trance II", makes the reader walk from the front door of Carl's Gran's flat through half-dark rooms, discovering floating texts which undergo change in font, size and style, provided that the reader keeps on reading for a long time, as shown in Figure 4. The door of the other room unlocks once all the portions of the narrative have been discovered. This part offers many hidden affordances. In Nightingale's Playground, if all the clues are not discovered, then the door to the next part will never unlock. The reading of the text shall remain incomplete.

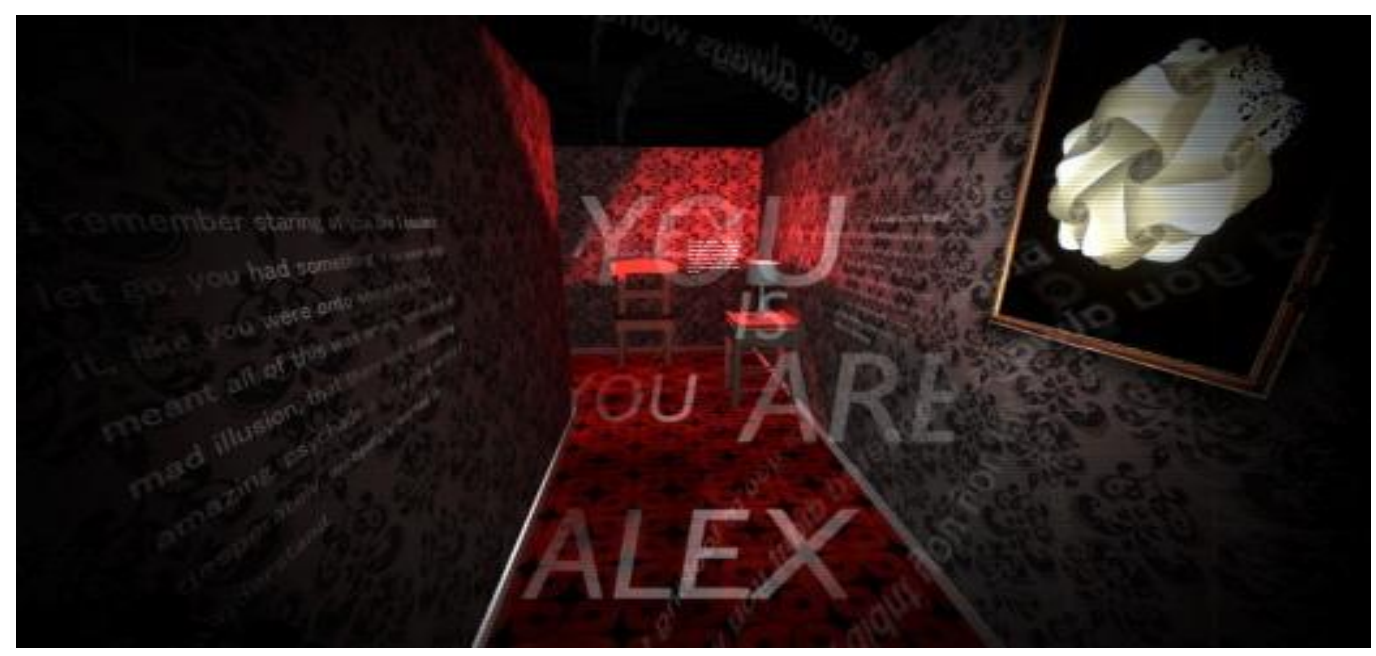

Figure 4: A visual from “Consensus Trance II”, Nightingale’s Playground.

Source of the image: ELMCIP website.

Even the performance of the characters inside the digital text offers hidden affordances to the reader. The readers will never get to see Carl or Alex on-screen but the rooms, belongings, and all the possessions of the characters make the readers feel their presence. Carl "actually questions Alex's existence" (Campbell and Alston). It could be interpreted as a metaphor "for his [Carl's] own conflict with his sense of the self". Perhaps the half-dark rooms are the metaphors for Carl's repressed memories regarding Alex. This duality within Carl turns into anxiety who engages himself throughout the narrative to seek the identity of Alex. Disturbed Carl's perplexity is distinctively focused by the author where a portion of the floating text switches between the name- Carl and Alex. This retains the suspense of the narrative where the reader delves through the narrative to find out the real identity of Alex. Affordances related to Carl's psychological state is scattered throughout the text, in all the narrative parts.

The "Fieldwork Book", the third narrative part of the story, is an old exercise book of Alex. The virtual exercise book is the only possession of Alex and the reader relates to it as the only firstperson referential voice of Alex. The pages of the book can be turned by dragging the mouse from page to page and as a reader moves forward he might smell more about the suspense related to the identity of Alex. The book is soil stained and virtual woodlice run around the pages, as portrayed in Figure 5. The book contains the scribbled handwriting of Alex, some suggestions and comments addressing Carl, some numbers which appear to be codes, scribbled disturbing sketches, bits of leaf stuck to the pages with sellotape, comments regarding Alex's assignment written in blue by the teacher and many more. Even Carl addresses Alex and writes a few lines for Alex. It seems as if the only communicative device between the two friends was this fieldwork book. The book also contains a newspaper cut-out of the game The Sentinel, famous among the gos kids and this game perhaps is the connective link between Alex and Carl which further leaves the reader with questions related to the identity of Alex. 


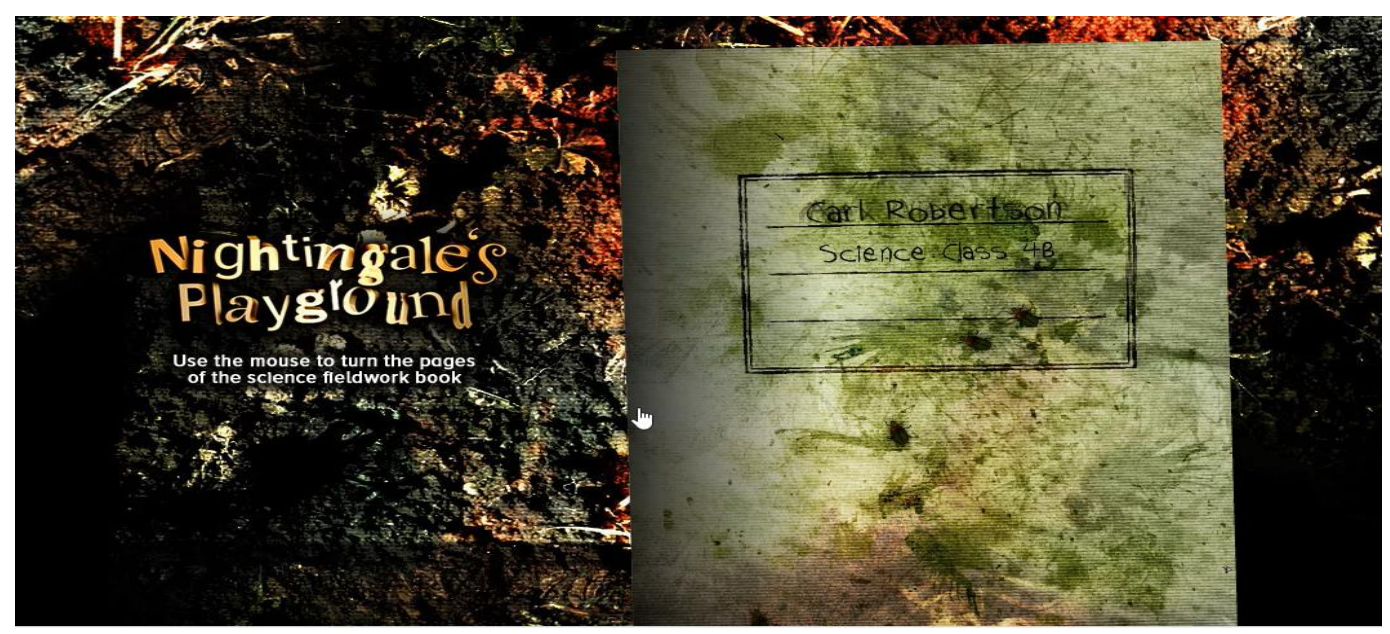

Figure 5: A visual from "Fieldwork Book", Nightingale's Playground

Perhaps the inquisitive reader who had several queries regarding the text will be somewhat satisfied when he shall go through the e-book, which provides a lot of background information about the digital plot. The e-book not only reflects upon the relationship shared by Carl and Alex but also throws light upon Carl and Gran's relationship. In this section Gran seems to be hiding the real facts related to Alex and Carl tries hard to convince Gran to reveal the identity of Alex but each time he tries, Gran either ignores or Gran asks him for a change of topic. In this section, the reader will even get to know about Carl's mother, but shall remain unaware about her presence.

The narrative has few connective common material possessions which have been mentioned by the author- the computer game The Sentinel, the red case, the fieldwork book. The suspense and the identity of Alex remain unresolved and the reader goes through each and every part to search for Alex's existence. All the four sections are useful for a better understanding of the text as a single unit. Thus, the affordances are perceptible only to unlock the narrative, leading the reader move from one room to the other. However, the characters within the digital text keep grooving for each other's real identity.

The graphics and the non-sequential characteristics used inside the text adds to an immersive and interactive quotient from the reader's side. The audio track and the minimal visibility might make the audience feeling claustrophobic but at the same time, it will push the reader to find the next clues of the plot leading through the dark game space both for Carl and for the readers. It leaves the readers to feel ambiguous and puzzled as they question- Alex's identity, Carl's anxiety, The Sentinel as a computer game or something mysterious, Gran's secretive nature, Carl's mother's absence, and so on. 


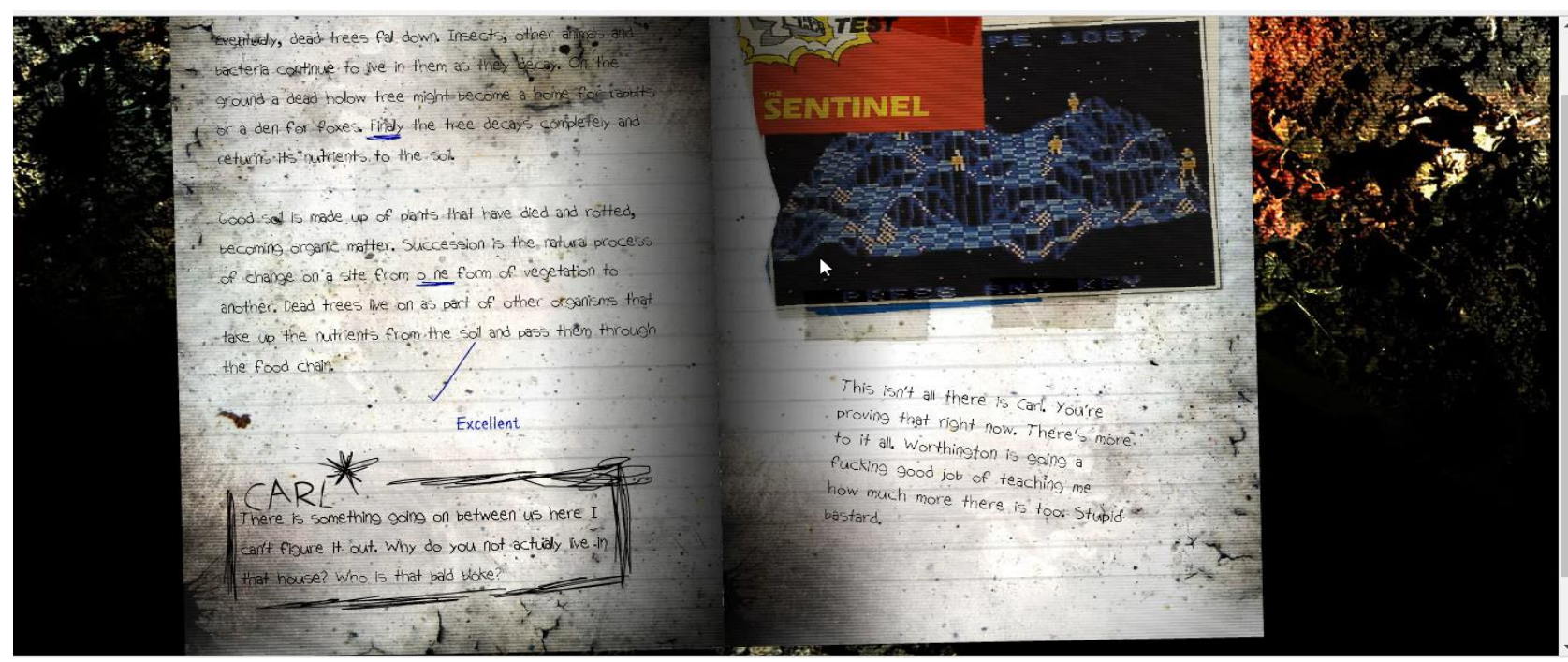

Figure 6: A cut-out of The Sentinel, a note (perhaps from Alex) for Carl, Carl's homework with comments from teacher, as depicted in the "Fieldwork Book", Nightingale's Playground

Such moments are rare indeed when a bibliophile takes up a story and is completely captivated by it. After reading the first part of Campbell and Alston's Nightingale's Playground this is exactly what usually happens. A story that defies the conventional method of reading and is read only on the computer screen excites the child inside a reader to know more about Digital Fiction. At the same time after going through the first part, the reader inside this researcher was perplexed because reading a digital text was almost a new genre. The researcher desperately wanted some guidelines on how to read a digital text or at least some review that are often found at the blurb of a new book. The search became fruitful when the researcher finally came across Edward Picot's review about Nightingale's Playground. This also offers a help to the digital reader to perform his role within the digital text better.

Edward Picot finds the Nightingale's Playground "enigmatic, complex, densely-texted, dark in tone, and technically highly accomplished" which definitely challenged the reader in this researcher to explore more about this text. Picot did mentions the four interlinked parts: a clickand-read interactive story, a ${ }_{3} \mathrm{D}$ game, a virtual exercise book and an e-book, but as an ignorant virtual story reader who was reading the text for the first time, somewhere one would expect more guidelines about how to unlock one episode to reach to the next. Picot further summarizes the storyline of each individual section, introduces the reader to the protagonist, Carl; provides hints about Carl's relationship with Gran and Alex but he reveals the ending of the text and this could kill the suspense lurking inside the reader who did not read the text yet. Picot even disclosed the climax of the narratives while discussing the $3 \mathrm{D}$ game. On the other hand, Picot's view regarding the shortcomings of the text was agreeable- structural weakness and graphic design may drive a reader, who is unfamiliar with new media, perplexed. Detailing and examining the text becomes difficult as it is inconvenient for the reader "to shuttle backwards and forwards between one section and another". Once the reader/player starts the journey he cannot stop in-between because if he does so, he will have to go through the text from the starting point. This might alter the mood of the reader and he may lose his interest. "A more serious flaw" according to Picot is that the Fieldwork Book and red vanity case seem "rather disappointing" as the contents within them do not satisfy the inquisitiveness of the reader. However, the Fieldwork Book is rather very important as it throws light on absent Alex's personality, strengthens the mysterious feeling as to why Gran 
was trying to hide some untold story related to Alex, helps Carl to understand Alex's perspective, and for the reader, the existence (whether in real or as an imaginary entity of Carl's mind) of Alex is ensured.

Picot also pointed out some phrases which could be difficult for the readers to negotiate with and these for him were less impressive. He perhaps is correct, but not completely. Out of them, two phrases definitely voice the anxiety pre-existing in the text. The phrase "mad illusion" is a strong emotive adjective as Alex's identity for Carl was almost an illusion. Again, "desperately, weepingly wanted to understand" expresses the helplessness of both the protagonist and the readers who feel claustrophobic within the room but still are desperate to know more about the absent Alex.

Picot, however, appreciates Campbell's approaches towards the creation of Digital Fiction. It "avoids the danger" of the reader to regard "the text as more than the images" and makes the reader/player "inherently immersive and interactive", according to him. Picot also admires Campbell's use of audio-track. He also feels a commonality that lies between the horror game The Path and the Nightingale's Playground. Even the themes and motifs of his earlier published short stories share common features with this text according to him. Picot analyses that adult life is constrained with the dullness of the ordinary world which is associated with adulthood whereas inner reality is associated with childhood. And perhaps, in Nightingale's Playground Carl, the adult narrator tries to re-discover his real self through his memories of his best friend Alex.

Besides that, psychoanalytically speaking, probably Carl is so engrossed with his game world that perhaps his consciousness blurs the line between the real and the virtual. Picot ends by raising several questions that are left open by Campbell and philosophize about life which "isn't about answers: its about questions". Though Picot's review has its shortcomings, it surely helps the confused reader to understand Nightingale's Playground better. Carl's mental condition is perhaps a performance. Whether he is really psychologically disturbed, pretends to search for Alex, has forgotten about his identity; are questions which leave the reader wander around the Digital Fiction to search for more clues. If hidden affordances are not perceptible, the performance of Carl shall remain misunderstood which can result in disoriented reading of the text. Thus, understanding Carl's psychological state of mind is equally important for the readers to negotiate with the multiple levels of the performance spaces offered by the programmer through the encoded clues. As already mentioned, affordances related to Carl's psychological state is scattered in all the narrative parts. To understand the characters condition of mental health is also a performative task for the readers. The reader has to remember as many signs (floating on the walls of the text) as possible. He needs to connect the links and try to associate them. To re-read a part of the text (especially the onlinetext and the game version), there and then (comparatively easier in a printed text where the reader can just turn the pages and continue reading), is perhaps difficult. Memory thus plays a very significant role. The player/reader has to recollect the signs and retain them in his memory. If he cannot recollect, he has to go back and start reading the text from the very beginning. This is how the reader can try to unravel the identity of Alex.

Carl's psychological state as expressed in the four parts of Nightingale's Playground also hints at the possible mental disorder the protagonist is undergoing through. Luc Herman and Bart Vervaeck suggest that Carl perhaps has had dissociative amnesia, a mental disorder that makes an individual experience disconnection and lack of continuity between thoughts, memories, surroundings, actions and identity. People with this disorder try to escape out of reality involuntarily and this creates disbalance in their normal behavioural traits in everyday life. Alan Kirby claims that in the $21^{\text {st }}$ century people are living in an age of autism, a developmental disorder that impacts the nervous system by impairing the ability to communicate and interact in the real 
world which has been reflected in many novels like Mark Haddon's The Curious Incident of the Dog in the Night-Time (2003), Ridley Scott's film Blade Runner (1982). The characteristics are similar to those of Carl and with both the protagonists of the novel and the film. These are- "infinite loneliness and alienation, emptied of reciprocity or intimacy, a mixture of vast silent space between affectless people and unbearable overcrowding, it suggests a social condition of almost universal autism" (Kirby 229). Carl is obsessed with the memories of Alex. Kirby also identifies that an autistic young person feels an "emerging generational crisis by which young people are felt by adults to be unreachable (Bettelheim's view of autists), necessarily distant, uncooperative, alienated; the (mis)identification of autism's "causes" in childish things (the MMT jab, other infant vaccines, videogames); Stuart Murray discusses the (illogical) media emphasis on autism as a child's illness" (Kirby 232). Alex's friend, the protagonist also finds that his grandmother and school authority are unable to negotiate his friendship with Alex.

The symbols guide the reader to react and to take decision in a particular manner. Reading a digital text offers an immersive experience, different from the printed text. Signs offer an imaginative space when reader reads a printed text. The same image when adopted on-screen, offers different experience. Nightingale's Playground offers both- printed and digital versions of the text. Semiotically, the blinking of an image is not possible in a printed text. This carries three performative functions of language carried out inside a digital text: (1) the codified meaning encoded by the programmer, (2) the decoded meaning as analyzed by the reader, and (3) the material tangibility of the sign inside the digital text where materiality of the object is determined by the readers who equate the image with the real-world image. Hence Roberto Simanowski claims: "if it is an event rather than an object then it really needs the screen rather than the page" (ELMCIP). Virtual reading is dependent on time-based parameters which operate through various programming languages. Alvaro Seica focuses on the performance of a digital reader and observes that there is a "void, a blank moment in time and space, forcing a quicker human reading, which often ends/begins as a creative process itself by way of incomplete association, metonymy and metaphor". Besides the diasthimas, Seica also notices the reading experience which influences the creative matrix and formulates a set of guidelines for the digital reader: (1) not to be afraid of not reading everything on screen, (2) to reject frustration and to get engaged with the interface, (3) not to skip any portion as far as possible and to be open to the feeling of discomfort, (4) to avoid "extracting meaning by merely considering stating strategies", (5) to read source code, (6) to read the surfaces.

The Nightingale's Playground provides affordances that are sometimes perceptible by the reader/player. The language of performance is driven by the programmer on two levels- (a) by the semantic and linguistic language offered by the text, and, (b) by the path selected by the player/reader through whom he understands the semantic and linguistic levels of narration. Nightingale's Playground also offers the digital readers a space to perform. The digital readers not only read digital text but also need to perform while reading the text. The digital texts too offer space of performance that is offered by the author of the digital text. The readers' ability to interact with the texts, to solve puzzles, to decode the meaning of the clues, etc. enables the digital texts to move forward. Thus, it has been observed that the digital text's meaning to be decoded is dependent on the performer and his performance space. 
10| Rupkatha Journal, Vol. 13, No. 2, 2021

\section{NOTES}

${ }^{1}$ A software program developed by Eastgate Systems for creating hypertext fictions.

${ }^{2} \mathrm{~A}$ genre of electronic literature where a reader chooses the link to move from one text to the other.

3 The abbreviation of VFX is Visual Effects and SFX is Special Effects.

${ }_{4}^{4}$ Property of an object or a sign which indicates to the users the required action they need to take.

\section{REFERENCES}

Aarseth, Espen, J. 1997. Cybertext: Perspective on Ergodic Literature. The John Hopkins University Press. Google Books. Accessed 21 Apr 2017 https://books.google.co.in/books?id=qx_-zjo-

TwoC\&pg=PP11\&source=gbs_selected_pages\&cad=3\#v=onepage\&q\&f=false

Bell, Alice. 2016. 'I felt like I'd stepped out of a different reality': possible worlds theory, metalepsis and digital fiction. Sheffield Hallam University. Pdf. Accessed 26 Sep 2020 from https://core.ac.uk/download/pdf/77594161.pdf

Campbell, Andy and Judi Alston. 2010. Nightingale's Playground. Dreaming Methods. Accessed 11 Apr 2017 from https://digitalfiction.dreamingmethods.com/nightingalesplayground/

Campbell, Andy and Judi Alston. 2010. Individual Work: Nightingale's Playground. Electronic Literature Directory. Dreaming Methods. Accessed 11 Apr 2017 from

https://directory.eliterature.org/individual-work/3723

Campbell, Andy and Judi Alston. 2010. ELMCIP. Accessed 11 Apr 2017 from https://elmcip.net/creativework/nightingales-playground

Herman, Luc and Bart Vervaeck. 2017. Minds in the New Media Ecology. DOAJ. Vol 18 No. 1. 14 Apr Pdf. Accessed 26 Sep 2020 from http://www.imageandnarrative.be/index.php/imagenarrative/article/view/1498/1204

Kirby, Alan. 2009. Digimodernism: How New Technologies Dismantle the Postmodern and Reconfigure our Culture. The Continuum International Publishing Group Ltd, London.

Kuchina, Svetlana. 2018. Electronic literary text: cohesion and coherence aspects. SHS Web of Conference. ICPSE. Pdf. Accessed 26 Sep 2020 from https://www.shsconferences.org/articles/shsconf/pdf/2018/16/shsconf_icpse2018_04014.pdf. https://doi.org/10.1051/shsconf/20185504014

Picot, Edward. (2011, Jan). Schoolboy Daze. The Hyperliterature Exchange. Accessed 11 April 2017 from http://hyperex.co.uk/reviewnightingale.php

Simanoswski, Roberto. 2010. What is and to What End Do We Read Digital Literature? Electronic Literature as a Model of Creativity and Innovation in Practice (ELMCIP). Pdf. Accessed 29 Sep 2017 from http://dichtung-digital.de/cv/Simanowski-

What\%2ois\%2oand\%2oto\%2owhat\%2oEnd.pdf

Wesolko, Dane. 2016, Jun 15. “The Theory of Affordances.” Medium. Online reading. Accessed 23 Jan 2020, 05: 02 p.m. https://medium.com/@danewesolko/the-theory-of-affordances-cb51fd138bze

“What is Digital Fiction?”. Reading Digital Fiction. Accessed 11 Apr 2017 from https://readingdigitalfiction.com/about/what-is-digital-fiction/ 